\title{
Individual Characteristics of Students in the Course of Professional Development (as Exemplified by the Ulyanovsk Region of Russia)
}

\author{
Svetlana Borisovna Gnedova ${ }^{1}$, Anna Valerievna Emelyanenkova ${ }^{1}$, Irina Victorovna Mikhailova ${ }^{1}$, Anastasiya \\ Sergeevna Sedunova ${ }^{1}$, Valentina Borisovna Salakhova ${ }^{1} \&$ Natalya Gennadevna Enyashina ${ }^{1}$ \\ ${ }^{1}$ Ulyanovsk State University, Russia \\ Correspondence: Svetlana Borisovna Gnedova, Ulyanovsk State University, L.Tolstogo Street, 42, 432017, \\ Ulyanovsk, Russia. E-mail: alfkazan@mail.ru
}

Received: September 27, 2014 Accepted: December 8, 2014 Online Published: December 30, 2014

doi:10.5539/ass.v11n7p168

URL: http://dx.doi.org/10.5539/ass.v11n7p168

\begin{abstract}
The purpose of the article is to disclose the objective laws of professional and personal development of students through the example of students of institutions of higher education in the Ulyanovsk region. The research has been done within the nomothetic approach. The process of professional development and specific features of students, such as perfectionism and conformism have been described in the article.
\end{abstract}

Keywords: professional development (professionalization), perfectionism, manipulative professions, individual style, attributive schemes

\section{Introduction}

In recent years there is a great interest to the investigations connected to the problem solution of personal and professional development, formation of professionalism, professional skill, search for the conditions and factors of increasing efficiency of the personnel activity (Mogilyovkin, 2007). According to the acmeological approach, a professional is considered as the subject of professional activity possessing a high level of professionalism of the personality and activity, having a high professional and social status which has been constantly aimed at developing and self-improving. The psychological essence of the problem of formation, formation of the professional, development of his personality relies on such concept as professionalization.

Professionalization is a formation of specific types of a person's labor activity on the basis of development of the set of its professionally focused characteristics (psychological, physiological, behavioural, working) (Bodrov, 2001). Professional development of the subject of work can be considered in four directions. Firstly, as a process of his socialization - adoption of social norms, transformation of social experience into his own professionally focused sets, interests, values. Secondly, as the personality development that consists in forming a person's professional abilities and motives of work and depends on the content of labor process, conditions of its realization, features of professional career, etc. Thirdly, as a professional self-realization of the individual in his walk of life. It is a professional way, a working career, a career of the personality. Fourthly, as a form of activity of the personality (Druzhinin, 2001).

The success in training of highly competent professionals depends to a great extent on the awareness by each of them of the abilities and the opportunity of effectively moving ahead to perfection heights. As an internal criterion of the professional growth each person has his own ideas about a high degree of conformity with his development (Emelyanenkova, 2005). There are the requirements imposed by a profession, on the one hand, and the highest valuable standards that have been formed on the other hand. This problem consists in correlating individually created standards with the available personal and professional qualities. In other words, socialization takes place in the direction set by a standard. It can be both positively and negatively directed.

One of the important components of educational professional activity of students is the formation of special qualities which will further characterize the identity of a future professional. Plasticity of personal traits also makes the task of correct establishing conditions for the professional growth so important and significant for those who are trained (Emelyanenkova et al., 2008). 


\section{Materials and Methods}

In the course of studies general theoretical and empirical methods have been used, as well as mathematical processing of the research results. Among general theoretical and psychological methods we will note the theoretical analysis of scientific sources on the research subject, and as well as the comparative and comparative analysis of theories on the declared problems. The methods of collecting information are presented most widely: an experiment method; a method of sociometry of Y. Moreno (1999); a polling method; psycho-diagnostic methods, namely: Kettell's 16PF (2000) questionnaire, a scale of self-assessment and level of claims by T. Dembo and S. Y. Rubinstein, A. M. Prikhozhan's modification) (2007), V. I. Morosanova's multiscale polling technique "Style of behavior self-control" (SSPM) (1998), a technique" multidimensional scale of perfectionism" (P. L. Hewitt, G. L. Flett), in I. I. Gracheva's (2006) Russian-speaking adaptation, a technique "Styles of thinking" by Alekseev - Gromova (Russian-speaking adaptation questionnaire In Q: Harrison A. F. Brainson R. M. 1984) (Alekseev \& Gromova, 1993), a questionnaire of "A career anchor" by E. Sheyn (in V. E. Vinokurova's adaptation and V. A. Chicker) (2003), a method of semantic differential of Ch. Osgud (I. Solomina's modification) (Solomin, 2000). The choice of statistical information processing methods depended on the objectives at each stage and the project of researches: descriptive statistics, distinction coefficients of Mann-Whitney's criterion and multifunctional statistical criterion $\varphi^{*}$ - Fischer's angular transformation, coefficients of correlation interrelations (Ch. Spirmen), the cluster analysis.

The study was conducted among the students of the following institutions of higher education: Ulyanovsk state university, Ulyanovsk state pedagogical university named after I. N. Ulyanov, the Ulyanovsk highest aviation school of civil aviation (institute), the Ulyanovsk branch of Moscow pedagogical state university. In total, with a different set of techniques, 795 students at the age of 18 - 24 years took part at different investigation phases.

\section{Results}

Work on psychological portraits within university is conducted with the use of several techniques, but Kettell's questionnaire 16PF has always been the core method. The objective of this research stage was to study the features of a psychological profile of university graduates in professions like "people - people". According to the task, all specialties were divided by us into two groups. The professions relating to the "person- person" type were included in the first, namely: "psychology", "social work", "medical business", "law", "management" professionals of all these fields of activity have an opportunity or a duty to have influence on people, to change them; that is, to make impact on people, "to manipulate" them. Representatives of all other types of professions were referred to the second group: "person - machinery", " person - sign", " person - nature" and " person artistic image", namely the graduates of the faculties: mechanic-mathematical, physics and technology, information and telecommunication technologies, ecological, culture and arts, finance and accounting.

Statistically significant distinctions (mathematical data processing was carried out with use of Fischer's angular transformation) were obtained on both basic and on secondary factors of the questionnaire. Specialists of "manipulative" professions are characterized by greater domination, authoritativeness and aggressiveness; social courage, enterprise and impulsiveness; sensitivity, good nature and intuitivism; concentration, intensity and increased motivation; emotionality and difficulties in decision-making because of the abundance of thinking; and as well as a more developed communicative competence. Some of these features and related personal characteristics we will consider in more detail. Firstly, the studies of domination and motivation of the power in connection with professional preferences of testees emphasize the prevalence of expressiveness of a special need and aspiration to the power in a number of the "manipulative" professions relating to the sphere of "personperson". During our dissertation research (Emelyanenkova et al., 2008) the analysis of the power motivation (by means of the author's modified projective technique) on areas of basic education among 470 testees showed the most significant results while comparing the basic economic education and education in the humanities with natural - scientific and technical education in favor of the first group that also leaves us within the hypothesis of "manipulative" professions. Thus, the greatest internal conflict (at levels of 0,01 and 0,001 ) associated with the equally high aspiration to power but power avoidance was shown by the testees with the basic education in the humanities, both men and women. The striving to power is more marked in testees - men with economic (p $<0,05)$ and humanities education $(\mathrm{p}<0,05)$. Highly reliable low figures on motivation of power are characteristic of the people with the basic technical education.

Secondly, in this research significant distinctions in intelligence parameters (factors "B", "M", "Q1") depending on a scope of education and features of professional activity have not been revealed. The hypothesis of significant distinctions in the structural features of intellectual potential of students with different type of professional education has been put forward: the system "person- person" (students of the humanitarian faculty 
of Ulyanovsk state university and the system "person -sign" (students of the mechanic-mathematical faculty of USU). The sample group amounted to 94 people, for the complex diagnostics of whom intellectual qualities were used: R. Kettell's "CFIT" (Denisov \& Dorofeyev, 1996); "Intelligence structure" R. Amthower (Yasyukova, 2007); "Styles of thinking" Alekseev - Gromova (Russian-speaking adaptation of a questionnaire InQ: Harrison A.F. Brainson R.M. 1984) (Alekseev \& Gromova, 1993); "Style self-control of behavior" V. I. Morosanova (1998); motivations of professional and educational activity. No significant distinctions between the sample groups of students with technical and humanitarian education areas were revealed on the levels of expressiveness of such important constituent in the structural and substantial component of intellectual potential as general intelligence. Significant distinctions (Mann-Whitney's criterion) at level $p<0,01$ were found on a number of style characteristics of intellectual activity, self-regulatory and motivational characteristics. The sample group of people with technical education is distinguished by less marked motivation of their own activity, than in people with education in the humanities; a strong marked analytical style of intellectual activity, that is a tendency to the systematic analysis of problems, negative attitude to the uncertainty, interest to technologies, information search; and also more developed mathematical and spatial abilities. This phenomenon can be explained by the specificity of professional education or peculiarities of professional self-determination which is the result a conscious choice of a specialty on the basis of interests and abilities.

Thirdly, speaking about the communicative block of personal features, we will note that in one of our last reports (Emelyanenkova, 2008) we analyzed a psychological profile of USU graduates of the specialty "Psychology" and compared them with the data on features of communicative behavior in psychologists-consultants who are beginners. The result of the analysis was the statement that as an outcome of higher education training the students -psychologists possess a developed communicative competence. They come into and support necessary social contacts well, possess developed perceptual abilities that are expressed in observation and attention to interlocutors. Nevertheless, there was an obvious lack of study of a psychologist's own emotional problems (that also was confirmed and in the present analysis, on "Q4" factor in particular) which needs to be overcome due to individual or group experience of the psychotherapeutic work which is carried out in the period of university and postgraduate training (Emelyanenkova et al., 2008). Thus, graduates of "manipulative" professions have a number of the personal features distinguishing them from the representatives of other profession groups. There is a posed question about the cause and effect relationship as it is not known to what extent these features had influence on the choice of a profession, and in what measure the training in a certain profession has a forming impact on the peculiarities of personality's traits of a future specialist; that opens up one of the prospects for our further investigations.

The study of career orientations in future specialists of our region, conducted by A. V. Emelyanenkova and T. V. Nikulushkina (2010) became continuation and extension of this project. The type of a career realized by each person is a peculiar answer to a question "Who I am? ". Everyone has a certain set of motives, values which influence his or her choice, past life experience forms a certain system of valuable orientations, social attitudes in relation to a career therefore in the professional plan the subject of activity is considered through the system of its dispositions, valuable orientations, social attitudes, interests, etc. The concepts "career orientations" or the term of "a career anchor", introduced by E. Sheyn corresponds to it in American social psychology. Using "anchors" it is possible to predict, what type of a career will turn out for a person to be the most satisfactory as people try to choose a way of life according to the most important values for them (Misinformation, 2007).

We considered it important to find out, what the students are focused on, what motives they are guided by at the beginning of their work therefore 88 university graduates of Ulyanovsk of various specialties at the age of 18 24 years became participants of the study of career orientations. To obtain the most indicative information we compared the sample group of students of the Ulyanovsk region and the all-Russian sample group of the students, presented by V.A. Chicker (2003). By the study results we obtained profiles of career orientations in these two sample groups (see figure 1).

On the chart we can see that the uniform distribution of estimates on all career orientations is characteristic of the all-Russian sample group of students. Thus, the most frequent are the orientations "stability" and "service". Such results can point out about the importance of constancy in professional life for students, necessity of some guaranties, and also that their activity brought benefit to those who are around them. The situation seems to be expedient owing to the lack of experience, and consequently their readiness to sacrifice some moments (for example, time, personal interests, etc.) for the sake of improving professional competences. More rare career orientations "professional competence" are chosen $\left(\varphi^{*}=1,98 ; \mathrm{p}<0,02\right)$, "autonomy $(\varphi *=1,92 ; \mathrm{p}<0,02)$ and " lifestyles integration ", i.e. to students as future professionals it is important to improve their skills and develop 
in the chosen professional area, and also harmoniously combine professional activity with other spheres of their life.

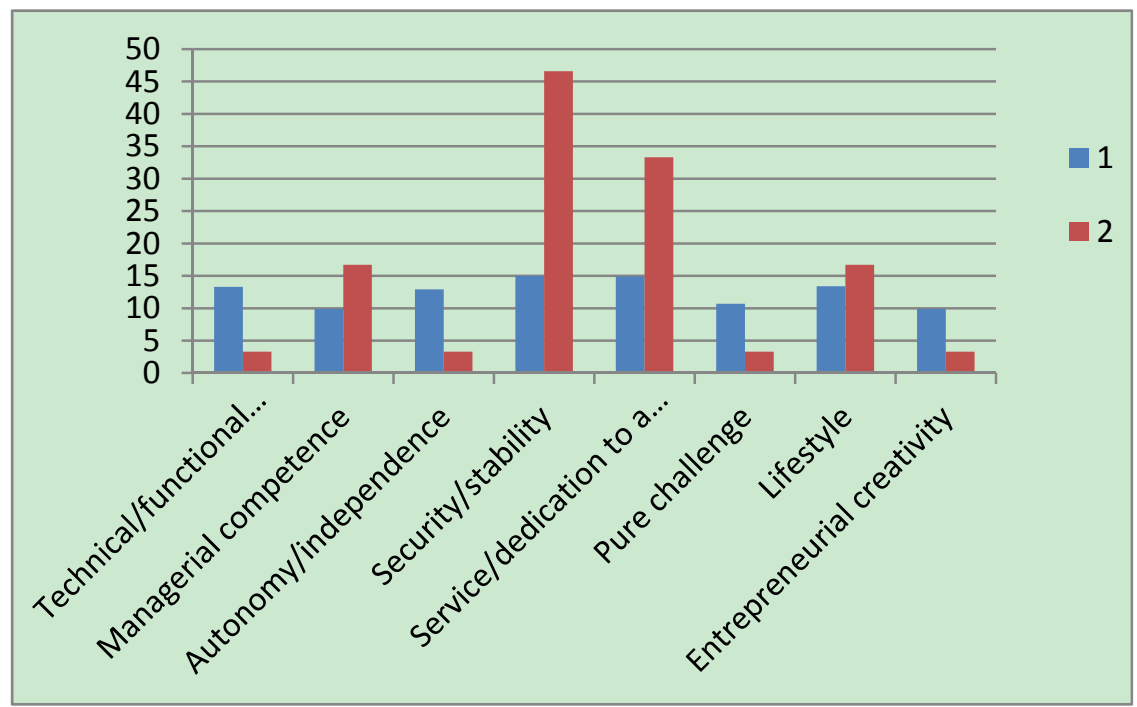

Figure 1. A frequency of elections of career orientations of the personality in students of the all-Russian sample group and sample group of the Ulyanovsk region (\%) (1 - the all-Russian sample group of students, 2 - sample group of students in the Ulyanovsk region)

For the sample group of students in Ulyanovsk also the most frequent chosen career orientations are "stability" $\left(\varphi^{*}=3,67 ; \mathrm{p}<0,00\right)$ and "service" $(\varphi *=2,26 ; \mathrm{p}<0,01)$, but their frequency is much higher than in the all-Russian sample group. It can be associated with their desire to build a career in their hometown. Besides, severe competitive conditions of labor market in the region force to appreciate constancy to a great extent, than to take risk. And the frequent choice of orientation "lifestyles integration" testifies that the balance between all spheres of life is also necessary for them, i.e. students in the Ulyanovsk region, are most likely to retain also due to the existence of a family, friends, a habitual, stable focus of interest. And the choice of career orientation "management" testifies about an active wish of students to realize themselves, including in their own projects. For more detailed definition of a career orientation specificity of the students in the Ulyanovsk region we analyzed in addition a semantic structure of their professional motivation (Solomin, 2000). According to results of the semantic analysis the most significant specific needs for the students in the Ulyanovsk region were those that are associated with the realization of administrative potential in the future which is in conformity with the general profile of career orientations. We can assume that students nevertheless connect hopes for future self-revealization and realization of their potential with an experience gain, skills. At the same time the specific needs connected with stability of life that fell into the sphere of basic requirements, are fundamental, underlying. They are subjectively recognized as satisfied - students have an internal feeling of security, existence of a very important support (Emelyanenkova \& Nikulushkin, 2010).

Therefore, it is possible to state that qualitative distinctions take place in profiles of career orientations among students of the Ulyanovsk region in comparison with a profile of career orientations of the all-Russian sample group.

The third project which is going to be considered now, touched upon one of the possible causes of professionalization peculiarities in students of provincial institutions of higher education and is based on the concept of "perfectionism". The conducted empirical research by A.S. Sedunova (2013), was aimed at identifying the role of perfectionism in the structure of style characteristics of a personality. We assumed the interrelation of perfectionism components with the general level of self-control of a personality, and also with a number of its style characteristics, in particular, with an assessment of productivity of activity and modeling of activity conditions (Sedunova, 2013). 70 senior students of various specialties took part in the study.

Verification of selective data on compliance of selective distribution to normal (One-Sample Kolmogorov-Smirnov Test, SPSS) showed that such compliance can be established for perfectionism indicators. At the same time for regulatory and personal characteristics and a scale "planning" selective distribution differs 
from normal values towards the values exceeding a grade point average (negative asymmetry) that allows us to assume about the raised level of development of these style characteristics in the student sample group. The problem of perfectionism was very important for professionals-beginners - a percentage ratio of the sample group is that the one tenth part of students will be in "a risk zone" of developing disadaptive perfectionism, that is in the range below a conditional norm.

The psychological profile of students with various levels of perfectionism was made up. Profiles of average values practically are not crossed, clearly demonstrating a higher level of style characteristics development in a group with high (but not excessive) perfectionism. The main results of the comparative analysis by means of Mann-Whitney's statistical criterion showed that students with high level of perfectionism are distinguished by high flexibility of their behavior, a developed ability to model the conditions of their own activity, including professional, and also a level of general self-control. Representatives of this group are capable of changing "settings" of the self-control system depending on a change of external and internal conditions which they can trace very quickly. At the same time the development of such trait as perfectionism can further lead to "a risk zone", to the development of disadaptation and neurotic symptoms.

Students with low level of general perfectionism are distinguished by the average level of requirement for planning of their own activity, prefer to work spontaneously. They tend to pay more attention to attempts of control over time (that is confirmed by the correlation analysis results - the negative interrelation of perfectionism with the general scale of time-urgent addiction of a technique "An index of time- urgent addiction" by O. L. Shibko was obtained).

Positive interrelations (Ch. Spirmen's coefficient) of general level of self-control and perfectionism oriented to others; and also significant positive correlations of the scale "modeling" with perfectionism components focused on himself and focused on others allow to assume the role of both individual and interpersonal factors. High rates on the scale "modeling" assume an ability to determine significant conditions of achieving the targets in both professional activity and communication activity, to estimate compliance of obtained results to the accepted purposes situationally and in the long term. Thus, the answer to a question as perfectionism and its structural components with style characteristics of self-control are interconnected was given.

One of the brightest projects in the series of our investigations was the study of how much the students of provincial institutions of higher education are inclined to conformal behavior demonstration in professional and life situations, and also attempt to reveal the attributive scheme of this behavior (Mikhaylova, 2011). To achieve the goals set the field and laboratory experiments were developed and carried out by us. 130 students of various institutions of higher education in the Ulyanovsk region of the Russian Federation aged from 19 to 26, out of them $70 \%$ of girls and $30 \%$ of boys participated in the study.

As a result of the first experiment which was developed in such a way that the false group persuaded a testee to see the object which was beyond of his perception, we found $13 \%$ of conformal students. The second experiment was developed in such a way that the false group persuaded a testee to feel a certain taste. Here we obtained the data different from the first experiment: we found already $70 \%$ of conformal students.

Further all agreeable testees of the two experiments were interrogated. In the course of data processing of field experiments by us it was found out that slightly more than a half of testees ( $65 \%$ of respondents) show conformal behavior. The obtained results significantly differ from classical experiments (Asch, 1951). We assumed that evidence of a situation has impact on manifestation of conformal behavior. In a situation with visual perception of an object that actually did not exist, the percent of conformal people is lower, than in differentiation of own taste.

Further, our task was to expose a type of attributive process in testees who showed conformal behavior and those testees who showed independent behavior. At that moment the testees did not know yet that they had become the participants of the experiment, they showed in $64 \%$ attribution of responsibility and in $36 \%$ of cases - causal attribution. As soon as testees learned about the experiment, they revealed only causal attribution of different types (the adverbial - adverbial attribution $-50 \%$, object attribution $-29 \%$ of testees, personal attribution $21 \%)$.

In the course of conducting these experiments "noise" was revealed - factors which could affect study results. Also in the course of field experiments we did not have an opportunity of profound studying individual characteristics of students. Therefore we made a decision to conduct laboratory experiments. During laboratory experiments students in the majority of cases (71\%) showed conformal behavior. 
We studied their self-assessment and level of claims by means of a self-assessment scale and level of claims by T. Dembo and S. Ya. Rubenstein in A. M. Prikhozhan's modification to study individual characteristics of students profoundly (Prikhozhan, 2007). We obtained the following data.

Self-assessment level among the students who have shown conformal behavior and independent behavior, reliably differs only by the criterion of self-confidence $(2,322$ at $\varphi$ critical. $=2,31$ with $\varphi$ - Fischer's angular transformation method). The obtained data correspond to the results of other scientists. All other indicators, such as health, mind, character, authority, ability to do something by hands and appearance in students of the two groups do not differ reliably.

The results obtained during laboratory experiments confirm the data of our natural experiments. In a situation with visual perception of really nonexistent object, the percent of conformal people is lower, than in differentiation of their own taste feelings. It is associated with the fact that people are more certain about the visual perception, than of the taste. However this fact does not reduce the extent of trust of respondents to a legend of experimenters: both in the first, and in the second field experiments of $98 \%$ of testees believed the words of experimenters.

Further we determined a type of the attributive process by a polling method (Mikhaylova, 2013) in students who had showed conformal behavior and those who had showed independent behavior. All respondents showed causal attribution of a different type. The results obtained testify that in the created situation the students who have shown conformal behavior, show reliably more often an adverbial type of attribution $(11,116$ at $\varphi$ critical. $=$ 2,31 with $\varphi$ - Fischer's angular transformation method). Testees to a great extent try to explain their own behavior by the external causes that are independent of them, to a lesser extent - assume responsibility, explaining the behavior by personal features and objective factors. The students showing independent behavior, demonstrated more personal type of attribution $(10,26$ at $\varphi$ critical $=2,31$ with $\varphi$ - Fischer's angular transformation method $)$ and at the same time a fundamental error of attribution. Less often the explanations were created on the object type of attribution, and least of all was explanations on the adverbial type of attribution $(1,315$ at $\varphi$ critical. $=$ 2,31with $\varphi$ - Fischer's angular transformation method).

We believe that the subject builds the judgment on any true fact. His judgment can be distorted because of the group influence on the subject or, for example, because of the influence of an authoritative personality. In this case two types of such reaction are considered:

1) the person subjectively, either starts denying the possibility of his wrongful belief (explains his behavior by circumstances, either by the presence of another person, or his own subjective features.

2) the person subjectively, agrees with the possibility that he was mistaken. In this case he also starts explaining his behavior by different types of causal attribution (Kelley, 1972), but from an opposite position.

\section{Discussions}

1. A comparison of students study results of central (Chicker, 2003) and regional institutions of higher education (Emelyanenkova \& Nikulushkin, 2010) was the most topical for modern conditions (Chicker, 2003; Emelyanenkova \& Nikulushkina, 2010). Severe competitive constraints of labor market force the students of the Ulyanovsk region to appreciate in a bigger measure stability of a work place and residence when planning a career, and also to integrate lifestyle, to find balance of family and professional interests.

2. In comparison with the results obtained at adaptation of the multidimensional scale of perfectionism by P. Hewitt and G. Flett, the level of perfectionism of graduates differs from the level of the Moscow senior pupils. According to I.I. Gracheva, the level of perfectionism of the majority of testees with a total point within a standard deviation - from 160 to $204(182 \pm 22)$ can be considered as an average and can be viewed as a conditional "norm". In this study the empirical norm is in limits $171 \pm 23,5$ points, that is from 147,5 to 194,5 points. On the one hand, the average level is lower, than in the original study, on the other hand - the indicator of interindividual variability is higher.

3. Contemporary foreign authors also study general objective laws of formation of causal attribution and self-attribution. So A. Quiamzade (Quiamzade, 2009) from Geneva university, Switzerland and J. P. L'Huillier (Jean-Paul L'Huillier, 2009) from the University of Massachusetts, the USA, studied a situation when strawmen made unusual, beyond the legal framework, actions with capital investments and how these actions were copied by others (Quiamzade \& L'Huillier, 2009). Their research, in particular, showed that, as a rule, testees attributed knowledge of special, confidential information to the unknown initiator and followed him as if this knowledge is true. In our pilot study similar results were obtained: students also attributed certain attributes to objects and acted as if this attributing is true. Apparently, it is a universal norm. However, theoretical and then practical 
questions arise: how the pattern of attributing is formed and whether it is possible to correct it. In our research we tried to answer these posed questions.

\section{Conclusion}

As our researches have showed within a series of projects that students of provincial institutions of higher education (the Ulyanovsk region in particular) possess a structure specificity of professional development which is expressed in a number of the following features.

Firstly, graduates of different specialties of the Ulyanovsk region possess a pronounced specificity of motivational, intellectual and communicative features of the personality. There is a question about cause and effect relationships as it is not known to what extent these features had influence on the choice of a profession, and in what measure the training of a certain profession has a forming impact on peculiarities of personality traits of a future specialist; that opens one of the prospects for our further researches.

Secondly, career orientations "stability" and "service" are the most characteristic for the sample group of students in the Ulyanovsk region. It can be associated with a desire to build a career in the hometown, and severe competitive constraints of labor market in the region make them appreciate constancy in a bigger measure, than take risk.

Thirdly, empirical studies confirm the importance of perfectionism for professional development of the personality and interrelation of characteristics of perfectionism with features of personal self-control. It has been revealed that more than $10 \%$ of students of regional institutions of higher education are in "a risk zone" of developing disadaptation associated with overestimated indicators of perfectionism and personal uneasiness that it is necessary to consider when developing correction actions. Students - "perfectionists" possess the developed abilities to modeling of external and internal conditions of real activity, and possess significantly more flexible system of self-control, than "non perfectionists". At the same time in "perfectionists" the risk of urgent addiction formation is much lower.

Fourthly, the students of the Ulyanovsk region are distinguished by greater conformity of behavior in a situation of perceptual, instead of visual incentives. In a situation with visual perception of an object which actually did not exist, the percent of agreeable people is lower, than in differentiation of own taste feelings. We believe that it can be connected with late growing - up of the young and their immaturity and lack of confidence in themselves. The students who have shown conformal behavior to a greater extent try to explain their own behavior by external (object type of causal attribution) and to a lesser extent students assume responsibility, explaining the behavior with personal features.

The given results of the research, may be used in adaptation of young professionals, and also in social and regional work with the youth.

\section{References}

Alekseev, A. A., \& Gromova, L. A. (1993). Understand me correctly or the book how to find the style of thinking, to use effectively intellectual resources and to find mutual understanding with people (p. 352). St. Petersburg, Economic school.

Asch, S. E. (1951). Effects of group pressure on the modification and distortion of judgments. In H. Guetzkow (Ed.), Groups, leadership and men (pp. 177-190). Pittsburgh, PA: Carnegie Press.

Bodrov, V. A. (2001). Psychology of professional suitability (p. 312). Moscow.

Chicker, V. A. (2003). Psychological diagnostics of an organization and personnel (p. 176). St - Petersburg, Speech.

Denisov, A. F., \& Dorofeyev, E. D. (1996). Cultural free test of intelligence of R. Kettell (p. 17). St.-Petersburg, IMATON Publishing house.

Druzhinin, V. N. (2001). Psychology. The textbook for liberal arts colleges. St.-Petersburg.

Emelyanenkova, A. V. (2005). Psychophysiology of professional activity: Educational and methodical complex (p. 150). Ulyanovsk, USTU.

Emelyanenkova, A. V., \& Nikulushkina, T. V. (2010). Features of semantic structure of professional motivation of students of the Ulyanovsk region. Social competence and resilience of the personality of the multipolar world: integration of scientific knowledge. Researches, practice, education: Materials of the II International theoretical and practical conference (pp. 121-123). Ulyanovsk.

Emelyanenkova, A. V., Sedunova, A. S., \& Gnedova, S. B. (2008). Personality in manipulative professions: 
technologies for research and maintenance (p. 160). Ulyanovsk. ULGU.

Gracheva, I. I. (2006). Technique adaptation "a multidimensional scale of perfectionism" P. Hewitt and G. Flett. Psychological magazine, 6, 73-81.

Hewitt, P. L., Flett, G. L., Besser, A., Sherry, S. B., \& McGee, B. (2003). Perfectionism is multidimensional: A reply to Shafran, Cooper, and Fairburn. Behaviour Research and Therapy, 41, 1221-1236.

Kelley, G. (1972). Attribution: Receiving the Causes of Behavior.

Markovskaya, I. M. (1999). Sociometric methods in psychology (p. 46). Chelyabinsk: Publishing house of South Ural State University.

Mikhaylova I. V. (2013). Attributing elements in conformal situations. Theory and practice of social development, 8, 144-147. Krasnodar: OJSC Publishing house "HORS"

Mikhaylova, I. V. (2011). Cognitive factors of social knowledge. Simbirsk scientific bulletin. Ulyanovsk, 3(5), 66-72.

Misinformation. (2007). Chosen concepts of business. Theories which changed the world (p. 336). Moscow.

Mogilyovkin, E. A. (2007). Career growth: diagnostics, technologies, training (p. 336). St.-Petersburg, Speech.

Morosanova, V. I. (1998). Individual style of self-control: phenomenon, structure and functions in any activity of a person (p. 192). Moscow: Science.

Prikhozhan, A. M. (2007). Diagnostics of personal development of teenage children (p. 56). Moskvab Autonomous Non-Commercial Organization PEB.

Quiamzade, A., \& L'Huillier, J. P. (2009). Herding by Attribution of Privileged Information. Journal of Behavioral Decision Making, 22, 1-19.

Sedunova, A. S. (2013). Perfectionizm and styles of self-control of a personality. Theory and practice of social development, 8, 127-129.

Solomin, I. L. (2000). Identification of the hidden motivation of the personnel. The Third All-Russian conference "People and organizations: human resource management in the organization, organizational consultation, business psychology" (pp. 60-61). Moscow, St. Petersburg, IMATON Publishing house.

Vyboyshchik, I. V., \& Shakurova, Z. A. (2000). R. Kettell's personal multiple-factor questionnaire (p. 54). Chelyabinsk, Prod. South Ural State University.

Yasyukova, L. A. (2007). Test of intelligence structure of R. Amthower. St.-Petersburg (p. 80). IMATON publishing house.

\section{Copyrights}

Copyright for this article is retained by the author(s), with first publication rights granted to the journal.

This is an open-access article distributed under the terms and conditions of the Creative Commons Attribution license (http://creativecommons.org/licenses/by/3.0/). 